\title{
ON INCORPORATION OF PREDICATIVE EXPRESSIONS IN VERBAL COMPOUNDS*
}

\author{
TAKANE ITOH \\ Musashi University
}

\begin{abstract}
Following the basic idea of Selkirk 1982 and Lieber 1983 to deal with verbal compounds in terms of the argument structures of verbal heads, we examine verbal compounds incorporating predicative expressions. We propose a framework for analyzing the internal structures of verbal compounds, which is different in detail from either Selkirk or Lieber. Noting that adjectives and nouns do not take predicative expressions as their arguments though they can occur with predicative expressions that are non-argument adjuncts, we show that seemingly complicated data distribution is correctly predicted in the proposed framework.
\end{abstract}

1. Introduction. This paper is an attempt to develop a theory of verbal compounds ${ }^{1}$ along the lines of Selkirk 1982 and Lieber 1983, with the focus of attention on incorporation of predicative expressions.

Selkirk and Lieber argue that the generalization captured by the 'First Sister Principle' of Roeper and Siegel 1978 should rather be captured in terms of the argument structure of the verbal head of a compound. Roughly speaking, their claim is that all non-subject arguments of the verbal head must be satisfied within the compound, ${ }^{2}$ and that this

* Part of the idea developed in this article was included in my study presented at the monthly meeting of Tokyo University English Linguistic Circle on October 6, 1984; I am grateful to the participants of the meeting, especially Kinsuke Hasegawa, for valuable comments and suggestions. I am deeply indebted to Tokio Takahashi, who read an earlier version of this paper, for many helpful suggestions. I would also like to thank Mark Jewell for kindly and patiently acting as an informant.

${ }^{1} \mathrm{By}$ the term 'verbal compounds', we mean the compounds of the form $[\alpha-$ $\mathrm{V}$-suf] $]_{\mathrm{N} / \mathrm{A}}$, where 'suf' stands for the suffix -ing, -er, or -en (, which is meant to stand for the morpheme forming passive participles and adjectival passives). It is controversial whether the verbal/non-verbal distinction is necessary in the study of compounds. But, given that there exist some distributional differences (e.g. student evaluation of teachers vs. *student evaluating of teachers), we maintain the distinction and limit our scope of study to verbal compounds.

${ }^{2}$ Lieber, unlike Selkirk, claims that non-subject arguments must be satisfied outside of the compound in some cases, but, concerning verbal compounds in our sense, this rough statement holds in her framework. 
principle leads to correct predictions as to the acceptability of various verbal compounds. Selkirk and Lieber share this essential idea, though the two differ from each other to a large extent in detailed analyses. Here, we will not make a close comparison of the two approaches. Instead, sharing the basic idea with them, we will propose a framework that is different in detail from either of the two, and see how some sets of data discussed by neither Selkirk nor Lieber can be handled in our framework.

The verbal compounds with which we are mainly concerned are those which incorporate predicative expressions. As is observed by Roeper and Siegel 1978, verbal compounds with the suffix -en are parallel to adjectival passives rather than verbal passives in that, among other things, they do not take predicative expressions:

(1) Verbal Passive

a. John was elected President.

b. John was labeled selfish.

(2) Adjectival Passive

a. *John acts elected President.

b. *John seems labeled selfish.

(3) Verbal Compound

a. *a President-elected woman (acceptable only in the sense 'elected by President')

b. *selfish-labeled boys

The contrast between 1 and 2 suggests that verbs (including passive participles) can take predicative expressions whereas adjectives cannot. Then, the unacceptability of 3 leads us to assume that the V-en in an -en compound is an adjectival passive (i.e. a deverbal adjective) and is not a verb. This seems to be essentially on the right track. However, we find some -en compounds acceptable with predicative expressions incorporated:

When we say '(non-)subject argument', 'direct object argument', and so on, they refer to the argument that corresponds to (or is mapped onto) the (non-)subject, the one that corresponds to the direct object, and so on.

It is a matter of controversy whether the crucial distinction necessary for treating verbal compounds is the subject/non-subject distinction as is argued for in Selkirk (1982: 34-36) or the external/internal distinction in the sense of Williams 1981. (For an argument against Selkirk, see Williams 1984.) But the decision between the two does not affect our arguments, and therefore we leave the problem open. We employ the term 'non-subject argument', simply because it sounds more familiar. 
(4) a. thin-sliced ham

b. a white-painted bench

The contrast between 3 and 4 calls for some explanation. It must also be noticed that verbal compound adjectives with the suffix -ing allow predicative expressions to be incorporated:

(5) a. a nice-looking guy

b. odd-smelling gas

The contrast between 3 and 5 must also be accounted for. In what follows, we will examine how these and related data can be treated.

2. Framework. Following the insightful idea of Selkirk 1982 and Lieber 1983, we propose the following principle:

(6) Every non-subject argument of a lexical category $\mathrm{X}$ must be - satisfied as a sister of X.

This is a minor revision of Selkirk's (1982: 37) 'First Order Projection Condition'. Her condition states that all non-subject arguments must be satisfied 'within the first order projection of' $X$, where the first order projection of $\mathrm{X}$ is, roughly speaking, $\bar{X}$ immediately dominating $X$. In this formulation, as Tokio Takahashi has pointed out to me, arguments of $\mathrm{X}$ are allowed to be deeply embedded within $\overline{\mathrm{X}}$; for example, cases like the following are permitted:

( 7 )

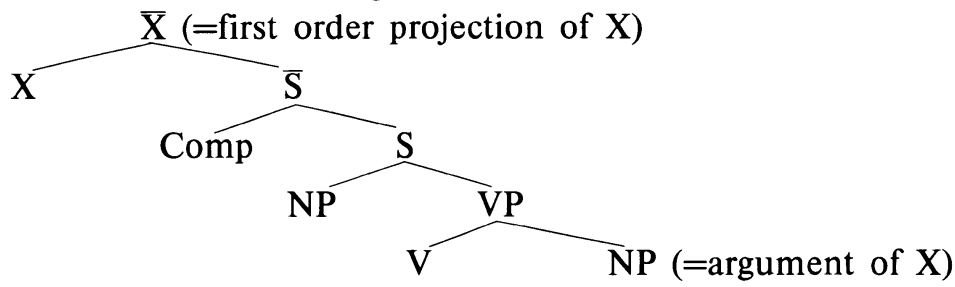

But of course this is not what is intended. Our revision is meant to exclude such undesired situations. In a syntactic phrase like the following,

( 8 )

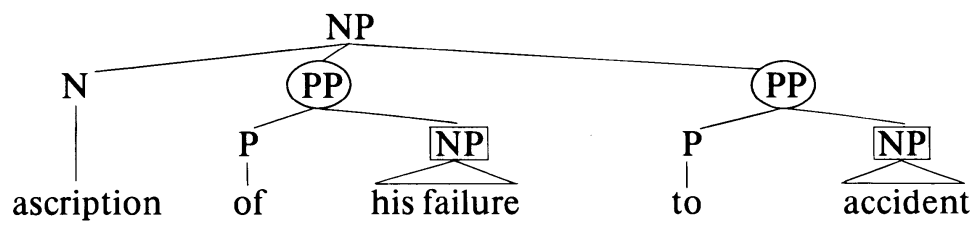

the boxed NPs are not the sisters of the head noun, but it is plausible to analyze the circled PPs rather than the boxed NPs as the arguments of the head. Thus the phrase in 8 satisfies 6 . 
The arguments of $\mathrm{X}$. are listed in the argument structure of $\mathrm{X}$, which is the part of the information contained in the lexical entry of $\mathrm{X}$ which specifies the number and types of the arguments $\mathrm{X}$ takes. For the purpose of exposition, we employ the well-known terms for semantic relations such as Agent, Theme, Locative, etc. to denote the types of arguments, though it is not obvious whether these terms are best-suited for representation of argument types. ${ }^{3}$ It is important to note that not all constituents bearing some semantic relation to $\mathrm{X}$ are necessarily arguments of $\mathrm{X}$. For example, locative PPs may appear with any verb denoting action:

(9) a. John ate pizza in the park.

b. Mary sliced ham in the kitchen.

We can hardly claim that the verb eat or slice takes a Locative argument (i.e. that the lexical entry of eat or slice is specified so as to take a locative phrase). Rather, the locative phrases in 9 should be analyzed as non-argument adjuncts of the VPs. This is in sharp contrast with the case of put, which, as is widely accepted, takes a locative phrase as one of its arguments. The Locative argument of put may be syntactically realized as a PP as in $10 \mathrm{a}$, an adverb as in $10 \mathrm{~b}$, or a particle as in $10 \mathrm{c}$, but it cannot be absent as shown in $10 \mathrm{~d}$ :

(10) a. John put the box on the shelf.

b. John put the box there.

c. John put the box down.

d. *John put the box.

In many cases, it is not very easy to determine whether or not a constituent is an argument of a lexical item, because argument-hood does not always coincide with obligatoriness (for example, though the verb eat can be used intransitively, it is unquestionable that pizza in 9a should be analyzed as an argument of eat). Yet, theoretically, a sharp distinction should be drawn between arguments and nonargument adjuncts, and our point is that not only arguments but also non-arguments may bear some semantic relations.

We assume that the so-called predicative expressions constitute a type of argument. Thus we analyze feel in 11a as taking two arguments Theme

3 As is argued in Jackendoff $(1972, \S 2.3)$, an argument of a verb may bear simultaneously more than two semantic relations to the verb. For example, in John sold a book to Mary, John bears two semantic relations agent and source. This might suggest that the terms for semantic relations are inadequate to represent argument types. 
and Pred (standing for 'Predicative expression'), and call in 11b as taking three arguments Agent, Theme, and Pred. ${ }^{4}$

(11) a. Silk feels smooth.

b. They call their son Bob.

Syntactically, smooth in 11a and Bob in 11b may be analyzed as an AP and an NP, respectively, or, more plausibly, both may be analyzed as small clauses, but in the argument structures both are of the type Pred.

Like the locative phrases in 9, predicative phrases can be non-argument adjuncts as in the following examples:

(12) a. John ate pizza uncooked.

b. Mary sliced ham thin.

In each example in 12 , the verb is analyzable, as in the case of 9 , as taking two arguments Agent and Theme, the predicative AP being a nonargument adjunct.

Assuming with Selkirk 1982 that only binary branching is possible in word structure, we have the following two possible structures of verbal compounds:
a.

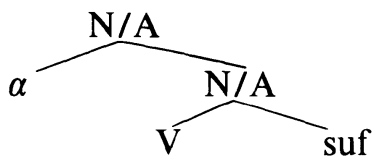

b.

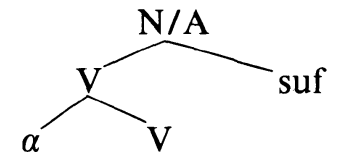

Selkirk argues that $13 \mathrm{a}$ is the only possible structure for all verbal compounds. Because there are in English no compound verbs of the form $[\alpha-\mathrm{V}]_{\mathrm{V}}$ where $\alpha$ is an $\mathrm{N}$ or $\mathrm{A}$, she argues, the structure 13b is impossible. But we do find verbs like hand-write, air-condition, deep-fry, deep-freeze, and so on. Even though this type of compound formation may not be very productive, ${ }^{5}[\alpha-\mathrm{V}]_{\mathrm{V}}$ is a possible compound structure.

${ }^{4}$ Quirk et al. (1972: 350-1) employ the term 'attribute' to denote the semantic relation a predicative expression bears to the verb. We may well employ this term instead of 'Pred' as the label of the argument type in question. In any case, I do not mean to claim that the notion of predicative expression should be treated on a par with the notions of semantic relations like agent or theme, which might be inadequate for representing argument types. See fn. 3 above.

It is important to note that we crucially disagree with Jackendoff $(1972, \S 2.2)$, who analyzes, for example, angry in John stayed angry as Locative and angry in George got angry as Goal. If we did not distinguish the argument type of predicative expressions from that of locative or goal expressions, our arguments below would collapse; the contrast between Shakespeare-ascribed (with Goal incorporated) and *mad-driven (with Pred incorporated), for instance, could not be accounted for.

${ }^{5}$ But Lieber (1983: 262-4) suggests that this type of compound formation is fully 
Then, though we do not find, say, truck-drive as an actual verb, we can analyze it as a possible (non-occurring) verb which acquires its full status as a word only when the suffix -er or -ing is attached to it. This is not an uncommon situation in word-formation; for example, as has often been discussed, un-prefixation derives such adjectives as unseen or uneaten, where the base -en adjectives do not actually occur as adjectives (*the seen enemy, *an eaten meal). ${ }^{6}$ Thus we may safely assume that both $13 \mathrm{a}$ and $13 \mathrm{~b}$ can be potentially assigned to all types of verbal compounds.

Given the two structures, our principle 6 can be interpreted as follows: if $[\mathrm{V} \text {-suf }]_{\mathrm{N} / \mathrm{A}}$ in $13 \mathrm{a}$ or $\mathrm{V}$ (at the bottom) in 13b takes a non-subject argument, it must appear in the position of $\alpha$. To put it differently, the principle 6 means that, when the head of a verbal compound takes a nonsubject argument, $\alpha$ must be interpreted as that argument, and that, if the head does not take any non-subject argument, $\alpha$ can be given a nonargument interpretation.

As Selkirk (1982: 37) points out, the principle 6 leads to the correct prediction that a word taking more than two non-subject arguments cannot be the head of a verbal compound, for there is only one $\alpha$-position in either structure in 13 .

(14) a. *the scholar's play-attributing to Shakespeare

(cf. The scholar attributes the play to Shakespeare.)

b. *John's failure-ascribing to accident

(cf. John ascribed his failure to accident.)

We assume that not only verbs but also (at least some) nouns and adjectives have their argument structures. In unmarked cases, a noun or adjective derived from a verb inherits the argument structure of the base verb unless otherwise specified in the grammar. Lieber 1983 assumes that a derived word does not inherit the argument structure of its base if its syntactic category is different from that of the base, so that a deverbal noun or adjective does not take any argument. But her assumption is not well-motivated. It is true that affixation sometimes involves somewhat unpredictable change of argument structure, as in the following examples:

productive where $\alpha$ is interpreted as a non-argument. This seems to be supported by the following examples, which Adams (1973: 109) reports to be 'often seen on the labels of clothes': hand-wash, cold-rinse, short-spin, warm-iron, hand-hot medium wash, line-dry. These give a strong support to our analysis.

6 See Allen $(1978, \S 4.2)$ for a detailed discussion of such cases. 
(15) a. ?*John invents (on weekends).

b. John is an inventor.

The contrast suggests that the verb invent, but not the derived noun inventor, takes the Theme argument obligatorily. But this does not mean that the noun inventor does not have an argument structure. The following examples show that nouns as well as verbs take arguments: ${ }^{7}$

(16) a. *He breaks.

b. ${ }^{*} \mathrm{He}$ is a breaker.

c. He breaks promises.

d. $\mathrm{He}$ is a breaker of promises.

(17) a. *John ascribed his failure.

b. *John's ascription of his failure.

c. John ascribed his failure to accident.

d. John's ascription of his failure to accident

Furthermore, there is some evidence to show that the noun inventor has its own argument structure. Selkirk (1982: 28-34) discusses an interesting contrast between tree-eater and tree-devourer; because the Theme argument is optional with eater, tree in tree-eater may be interpreted either as the Theme argument or as non-argument locative, whereas tree in tree-devourer can have only the Theme interpretation, because devourer takes the Theme argument obligatorily. This contrast itself could be accounted for in terms of the difference between the argument structure of the verb eat and that of the verb devour, for the derived nouns share their argument structures with their respective base verbs in this case. In this light, let us consider machine-inventor and weekend-inventor; machine in the former is interpretable as the Theme argument, while weekend in the latter is interpretable as a nonargument indicating temporal location. The fact that $\alpha$ in $\alpha$-inventor may be interpreted either as the Theme argument or as a non-argument shows that $\alpha$-inventor is parallel to tree-eater in the relevant respect. As we saw in 15 , the verb invent is like devour in that it takes the Theme argument obligatorily, while the noun inventor is similar to eater in that its Theme argument is optional. Then, it follows that the argument structure of the derived noun inventor rather than that of the base verb invent is relevant here; without assuming an independent argument structure for the noun inventor, the data cannot be given a reasonable account. The

7 Examples in 16 are cited from Allen 1978. She gives many other similar examples (pp. 160-1, 165-8). 
same argument holds concerning such compounds as factory welder, home brewer, and police inspector, where the non-heads are interpretable as non-arguments, given that the verbs weld, brew, and inspect cannot be used (at least for some speakers) without the Theme arguments.

The above arguments are strong enough, I hope, to reject Lieber's assumption in favor of our position that a deverbal noun or adjective has its argument structure.

As is implicit in our representation of the structures in 13, we assume that the suffix -en derives an adjective directly from a verb. Both Lieber 1983 and Selkirk 1982 make a different assumption; -en is attached to a verb to form the passive participle and an adjectival passive is derived in turn from the corresponding passive participle by $\phi$-derivation or conversion. But because -en adjectives share the distributional properties with -able adjectives, ${ }^{8}$ which we cannot assume to be derived from passive participles, I see no reason to assume the derivation of adjectival passives from passive participles. Lieber argues that, without this assumption, we cannot explain why adjectival passives always take the same form as passive participles, given that -en, unlike -ing or other suffixes, is realized as various allomorphs. However, as far as we assume that the adjective-forming suffix -en is the same morpheme as the participle-forming -en, her argument does not seem very strong. We only need to assume that there are various spellout rules in the grammar of English (presumably in the lexicon) which specify that, say, catch-en is spelled out as caught instead of catched. It does not seem strange that a so-called 'derivational' suffix (adjectiveforming -en) and an 'inflectional' suffix (participle-forming -en) share the same morpheme; in fact, the morpheme -ing is used both derivationally (in deriving nouns and adjectives from verbs) and inflectionally (in forming present participles). Therefore, we may safely assume that -en is a suffix that derives an adjectival passive directly from a verb. As we will see in the last section, our data cannot be accounted for without this assumption.

This concludes a sketch of the framework we propose. As far as I can tell, the data concerning verbal compounds dealt with in Selkirk 1982 or Lieber 1983 can be accounted for in our framework roughly in the same manner as in their treatment. And, as we will see, our framework

${ }^{8}$ For instance, the change in argument structure involved in -able suffixation is the same as that involved in -en suffixation given in 18 , so that -able adjectives are also unacceptable in sentences like 19. 
offers a neat treatment of the data in 3-5 and the like, which seem to be left unexplained within Selkirk's or Lieber's framework.

3. -en compounds. Let us consider incorporation of predicative expressions in -en compounds. Before turning to our data, however, we will look at some of the properties of -en compounds which we do not find in -ing/-er compounds.

3.1. As is well-known, suffixation of the adjective-forming -en involves a change in the argument structure, which can be roughly expressed as follows:

$$
\begin{aligned}
& \Downarrow \underset{\text { SUB }}{(\operatorname{Arg} 1,} \underset{\text { DO }}{\operatorname{Arg} 2, \ldots)} \\
& {[\mathrm{V} \text {-en }]_{\mathrm{A}} \quad(\operatorname{Arg} 2, \ldots)} \\
& \text { SUB }
\end{aligned}
$$

It is controversial whether the change should be captured in terms of the Direct-Object-hood of Arg 2 in the argument structure of the base verb (as argued in Wasow 1977) or in terms of the Theme-hood of Arg 2 (as assumed in Williams 1981). This is a complicated problem which we will not go into here; it is sufficient for our purpose to note that some such change always accompanies the -en suffixation. Consider the following well-known distribution of adjectival passives:

a. *John seems believed (to be) honest.

b. *John seems given gifts.

19a is ill-formed because John does not correspond to any argument of the base verb believe, which takes the (small) clause John (to be) honest as its Theme. 19b is ill-formed because John is not the Direct Object (DO) but is the Indirect Object (according to the Direct-Objecthood analysis) or because it is the Goal argument and not the Theme argument (according to the Theme-hood analysis). In other words, the adjective forming -en can be suffixed only if the base verb takes the DO (or Theme) argument, and then that argument is mapped onto the subject of the derived -en adjective.

The dots in 18 are meant to indicate that the remaining arguments, if the verb has any, are generally inherited by the derived adjective; for example, the Goal argument is inherited in the following pair of examples:

(20) a. The scholars attribute the play to Shakespeare.

b. In many books, you will find the play attributed to 


\section{Shakespeare.}

Incidentally, notice that the subject argument of the verb (usually Agent) is assumed to be left out of the argument structure of the derived adjective in 18; an agent by-phrase occurring with an adjectival passive (as in the island was uninhabited by humans) is analyzable as a non-argument adjunct (like the locative PPs in 9). In our context, this is supported by the fact that an agent phrase can appear outside a compound as in 21 ; to be compared is the ill-formedness of 22 , where arguments of the -en adjectives inherited from the base verbs (Goal in each case) appear outside the compounds.

(21) a. hand-made by Indians

b. ?factory-built by slaves

a. *scholar-attributed to Shakespeare

b. *reader-addressed to the editor

Given this change in argument structure, we can now see what predictions our principle 6 makes concerning -en compounds. Recall that we have the following two possible internal structures of an -en compound:

(23)

a.

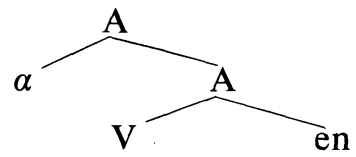

b.

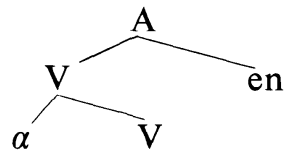

A verb with no non-subject argument (such as intransitive run) cannot appear in an -en compound; -en suffixation cannot apply because neither $\mathrm{V}$ in $23 \mathrm{a}$ nor $[\alpha-\mathrm{V}]_{\mathrm{V}}$ in $23 \mathrm{~b}$ has the DO (or Theme) argument. Hence the unacceptability of *a fast-run boy.

A verb taking only one non-subject argument (such as transitive construct, which has the argument structure (A A A nent, Theme)) can appear in an -en compound of the structure 23a. Because the verb construct takes the DO (or Theme) argument, -en can be suffixed to it to derive the adjective constructed with the argument structure (Theme). Because this adjective takes no non-subject argument, $\alpha$ can be interpreted as non-argument like locative, instrument, manner, and so on. Hence we have well-formed examples like factory-constructed, machine-constructed, and well-constructed. On the other hand, compounds of the structure $23 \mathrm{~b}$ are usually ill-formed with this type of verbs. The verb takes one non-subject argument Theme, which, according to 6 , must be satisfied in the position of $\alpha$ in 23b. Then, we 
will have, say, [ship-construct $]_{\mathrm{V}}$. But then -en suffixation is inapplicable because the compound verb ship-construct lacks DO (or Theme) argument. Hence the ill-formedness of $* a$ ship-constructed factory (in the sense 'a factory where ships are/were constructed').

But we find a set of examples where the compound verb $[\alpha-\mathrm{V}]_{\mathrm{V}}$ is analyzable as taking a DO (or Theme) argument: 9

(24) a. color-matched fabrics

b. tongue-tied students

c. a calorie-controlled diet

d. a starch-reduced diet

e. proof-read manuscripts

f. heart-broken girls

g. an air-conditioned room

In air-conditioned, for instance, air ( $\alpha$ in the structure 23b) satisfies the Theme argument of the verb condition, and the compound verb aircondition takes its own DO (or Theme) argument (as in they airconditioned the room), which makes -en suffixation applicable. By virtue of 18 , the Theme argument of air-condition is mapped onto the subject of the derived adjective air-conditioned, so that it is satisfied outside of the compound as in $24 \mathrm{~g}$. Corresponding to each example of this type, we find a phrasal expression reduce starch in one's diet, read the proof of the manuscripts, tie the students' tongues, or the like. It seems safe to claim that the type of compound formation exemplified in 24 is possible only if the corresponding phrasal expression of the form ' $\mathrm{V}$ (the) $\mathrm{N}_{1}$ of/in (Det) $\mathrm{N}_{2}$ ' (with the of/in phrase modifying $\mathrm{N}_{1}$ rather than $\mathrm{V}$ ) or ' $\mathrm{V} \mathrm{N} \mathrm{N}_{2}$ ' $s \mathrm{~N}_{1}$ ' is well-formed, where some strong relation holds between $N_{1}$ and $N_{2}$ presumably characterizable as ' $N_{1}$ is an inherent part or property of $\mathrm{N}_{2}{ }^{\prime}, \mathrm{N}_{2}$ inalienably possesses $\mathrm{N}_{1}$, , or something like that. In other words, only when $N_{1}$ and $N_{2}$ stand in some such relation can $\mathrm{N}_{2}$ be the Theme argument of the compound verb $\left[\mathrm{N}_{1}-\mathrm{V}\right]_{\mathrm{V}}$. In general, we may claim that the Theme (or DO) argument of a verb is '(strongly) affected' by the action denoted by the verb. Now, the compound verb in question denotes the action of ' $\mathrm{V}$-ing $\mathrm{N}_{1}$ ', for, as we saw above, $\mathrm{N}_{1}$ satisfies the DO argument of $\mathrm{V}$. Though the notion '(strongly) affected' is somewhat vague, it seems reasonable to assume that $\mathrm{N}_{2}$ can be '(strongly) affected' by the action of ' $\mathrm{V}$-ing $\mathrm{N}_{1}$ ' only if $\mathrm{N}_{2}$ bears some strong relation to $\mathrm{N}_{1}$. Thus a diet is

\footnotetext{
9 The examples in 24a-d are cited from Meys (1978: 161).
} 
(strongly) affected by 'reducing starch' in it, and a girl is by 'breaking her heart', and so on.

Notice, incidentally, that this type of compounds cannot be handled within previous frameworks such as Roeper and Siegel 1978, Selkirk 1982, or Lieber $1983 .{ }^{10}$ One might suggest backformation as a possible account; the verb air-condition is backformed from airconditioner or air-conditioning, and then the adjective air-conditioned is derived from the verb. But such an account is inadequate for examples like $24 \mathrm{~b}$, $\mathrm{d}$, where the corresponding verbs and -ing/-er compounds are either unacceptable or less common than the -en compounds. This type of compound formation in general appears less productive than other types of -en compound formation, presumably because the argument structure of the compound verb $\left[\mathrm{N}_{1}-\mathrm{V}\right]_{\mathrm{V}}$ is marked in that it takes a different Theme (or DO) argument from that of the head verb; thus we have airconditioned but not ${ }^{*}$ water-conditioned (swimming pool), heart-broken but not *leg-broken (girls). However, compound formation of the type 24c, d seems fairly productive; we may easily construct such examples as fat-reduced, salt-reduced, sugar-reduced. Then, these compounds should be given some reasonable account as in our framework.

A verb with two non-subject arguments such as ascribe or attribute can form an -en compound of the structure 23a. The verb ascribe, for instance, has the argument structure (A SUB the derived adjective ascribed has the argument structure (Theme, Goal). Because the adjective has only one non-subject argument (Goal), it can appear in the structure 23a if $\alpha$ is interpreted as the Goal argument. Thus we find well-formed examples such as the Shakespeareascribed play, an accident-ascribed failure. The b-structure is impossible with this type of verbs, because the verb has two non-subject arguments, both of which cannot be simultaneously satisfied in the $\alpha$ position in $23 \mathrm{~b}$.

To sum up, well-formed -en compounds have the structure 23a, except for the type of air-conditioned discussed above. Here, our intuition mentioned in the first section that $\mathrm{V}$-en in an -en compound is an

${ }^{10}$ Roeper and Siegel (1978: 234-5) claim that 24c, for instance, is related to be controlled for calories rather than to control calories. But such treatment seems inadequate at least for the examples $24 \mathrm{~b}, \mathrm{~d}, \mathrm{f}, \mathrm{g}$. 
adjective rather than a verb is captured; -en compounds have the astructure in most cases, where $\alpha$ is sister-adjoined to the derived adjective V-en.

3.2. Now let us turn to predicative expressions. As we saw in 2-3, which I cite below again, adjectival passives and -en compounds do not occur with predicative expressions:

(2) a. *John acts elected President.

b *John seems labeled selfish.

(3) a. *a President-elected woman

b. *selfish-labeled boys

Pointing out data like 2a, Wasow 1977 claims that such examples are ruled out because English grammar does not have a PS rule that expands AP as A-NP. Because it is plausible to rule out $2 \mathrm{~b}$ on the same grounds as 2a, we may interpret his idea as follows: examples like 2 are unacceptable because English PS rules do not allow an AP to dominate a small clause (or whatever syntactic category proposed as an analysis of predicative expressions).

But this PS rule account cannot explain the parallelism between 2 and 3 , for the examples in 3 can be generated by a PS rule that generates, say, a tall boy. Furthermore, the following examples show that APs can dominate predicative expressions: ${ }^{11}$

(25) a. The ham seems sliced too thin.

b. The bench was left painted white (though we once had a plan to repaint it).

Thus some different treatment is necessary for 2-3.

Let us consider the relevant data more closely. First, consider the following examples:

(26) a. We believe John honest.

b. We consider John a genius.

11 Judgments on examples like 25 are very subtle. Though my informant accepts 25 , he rejects examples like *his coffee seems served (too) hot, pointing out that to have been must be inserted after seems. He also suggests that thin in 25 a may be a $l y$-less adverb rather than a predicative AP; we may say the ham seems sliced too thinly, without changing the meaning. But at least in $25 \mathrm{~b}$, it is unquestionable that a predicative expression is dodminated by AP. In any case, it seems that we need to make closer examinations of similar examples. Even if we were led to conclude that sentences like 25 are basically ungrammatical (with $25 \mathrm{~b}$ accepted somewhat exceptionally), we would still need the stipulation in 43 to account for the parallelism between 2 and 3, and therefore our arguments would not collapse. 
c. We found the first page missing.

Phrases like honest in 26a, a genius in 26b, and missing in 26c are sometimes called predicative expressions. But we should rather analyze the verb in each example in 26 as taking the Theme argument as the only non-subject argument, which is satisfied by the post-verbal string of words (e.g. John honest in 26a) presumably analyzable as a small clause. This analysis reflects the fact that, in $26 \mathrm{c}$ for instance, what was found is not the first page but rather the fact that the first page was missing. Also, note that the sentences in 26 are nearly synonymous with the corresponding ones in 27 , where the verbs undoubtedly take that-clauses as their Theme arguments:

(27) a. We believe that John is honest.

b. We consider that John is a genius.

c. We found that the first page was missing.

Then, the phrases honest, a genius, and missing in 26 are not predicative expressions in the sense relevant to our discussion. Incidentally, the -en compounds corresponding to 26 are unacceptable:

(28) a. *John seems honest-believed.

b. *John seems genius-considered.

c. *The first page was missing-found.

This is because the subject John or the first page does not correspond to any argument of the verb believe, consider, or find. As we saw in 18, an -en adjective requires that its subject correspond to the DO (or Theme) argument of the base verb.

In some cases, it is not obvious whether a verb takes a clausal Theme argument as in 26 or takes the post-verbal NP alone as its Theme. But in examples like the following, non-clausal analysis seems plausible:

(29) a. We caught the girls naked.

b. We detected the boys drunk.

(30) a. His words drove the policeman mad.

b. John sent his wife mad.

(31) a. We elected a woman President.

b. We call our dog Pochi.

c. They labeled the boy selfish.

The verb catch in 29a is used in the sense 'find unexpectedly', and detect in $29 \mathrm{~b}$ means approximately the same as catch in $29 \mathrm{a}$. Thus these verbs appear semantically close to find in 26c. But the post-verbal NP in the construction of the type 29 is different from that in the believe-type construction in 26 in that it must denote human (or, presumably, 
animate) beings:

(32) a. ?*We caught the room full of smoke.

b. *We detected gas smelling.

(cf. We found faith lacking everywhere.)

In other words, the verbs catch and detect impose selectional restriction on the post-verbal NPs, which is not the case with find. This gives us evidence against the believe-type analysis of catch and detect.

The post-verbal NP in the so-called causative construction of the type 30 is also analyzable as the Theme argument of the verb; this construction is semantically close to the construction with the verb, say, persuade, as in we persuaded John to leave, where the status of the $\mathrm{NP}$ John as the Theme argument of persuade is well-attested. ${ }^{12} \mathrm{We}$ find selectional relation holding between the verb and the post-verbal $\mathrm{NP}$; in the case of send or drive, the post-verbal NP must be human, so that we cannot say *the crash sent/drove the car unusable.

The Theme-hood of the post-verbal NPs seems most obvious in 31 ; it is intuitively implausible to analyze the verbs in 31 as taking clausal (i.e. propositional) Theme arguments. Here, again, we find selectional restriction imposed on the post-verbal NPs; for instance, the postverbal NP must be human in the case of elect, and at least non-expletive in the case of label:

a. *We elected faithfulness our motto.

b. *They label it cloudy.

We may also note that none of the verbs in 29-31 takes a that-clause as the Theme argument: *we caught that the girls were naked, *John sent that his wife was mad, *they labeled that the boy was selfish.

Thus we may safely conclude that the structure of the sentences in 2931 is different from that of the sentences in 26; in 29-31, the postverbal NPs alone are the Theme arguments of the respective verbs, so that the phrases following those NPs are analyzable as predicative expressions in our sense.

Now, -en compounds incorporating these predicative expressions

12 Given this similarity between the constructions in 30 and the constructions with persuade-type verbs, we may analyze these verbs as having the argument structure (Agent, Theme, Pred), where the Pred argument corresponds to the infinitival complement. Then, as Kinsuke Hasegawa has suggested to me, the illformedness of *our persuasion of John to leave and *John is persuasible to leave may be treated in the same manner as that of 41-42. 
are unacceptable:

(34) a. *naked-caught girls

b. *drunk-detected boys

(35) a. *mad-driven policemen

b. *mad-sent wives

(36) a. *a President-elected woman

b. *a Pochi-called dog

c. *selfish-labeled boys

Compare these with the following cases, where -en compounds are acceptable:

(37) a. She sliced ham thin.

b. We painted the bench white.

c. They freeze fish fresh.

d. We caught a wolf alive.

(38) a. thin-sliced ham

b. a white-painted bench

c. fresh-frozen fish

d. a live-caught wolf

Meys (1975: 162-3) cites similar examples like hard-boiled eggs, readymade parts, the ready-set stage. A crucial difference between 29-31 and 37 seems to lie in the argument-hood of the predicative expressions. As we discussed in $\S 2$, predicative phrases may be non-argument adjuncts. It seems intuitively clear that this is the case with the sentences in 37 , whereas the predicative expressions in 29-31 are analyzable as (lexically specified) arguments of the respective verbs.

As a piece of evidence, we may note the difference in implicational relation. If we compare each sentence in 29-31 with the corresponding sentence without the predicative expression, we find that the truth conditions of the two are very different. Thus $30 \mathrm{~b}$ does not imply that John sent his wife, 31 b does not imply that we call our dog, and 29a does not imply that we caught (or seized) the girls (as is clearer if we consider the sentence he caught his wife out, where his wife could not be caught). The sentence we detected the boys means that we detected or noticed the presence of the boys, and they labeled the boy means that they attached a tag or sticker to the boy, so that the truth conditions of these sentences are quite different from those of $29 \mathrm{~b}$ and $31 \mathrm{c}$, respectively. To put it differently, the meaning of each verb in 29-31 is different from that of the same verb used without a predicative expression. For example, the verb send or drive does not have the 
causative meaning when used without a predicative phrase though it does have that meaning in 30 , and the verb catch means 'to seize' in a construction without a predicative phrase while it means 'to find unexpectedly' in 29a. Then, we may claim that the verbs in question require the presence of predicative phrases, that is, they take predicative expressions as their (lexically specified) arguments, when used with the meanings exemplified in $29-31 .^{13}$ On the other hand, if a sentence in 37 is true, the corresponding sentence without the predicative phrase is also true; thus $37 \mathrm{a}$ implies that she sliced ham, and $37 \mathrm{~b}$ implies that we painted the bench, and so on. Then, it is safe to analyze the predicative expressions in 37 as non-argument adjuncts.

We may also note the following contrast in support of our analysis:

(39) a. ?We sliced ham thin, and they did so thick.

b. ?We painted benches white, and they did so red.

(40) a. *My mother calls me Bob, and my father does so Robert.

b. *John sent Mary angry, and Bill did so mad.

Though the sentences in 39 may not be perfect, they are acceptable and far better than those in 40 , which are totally unacceptable. This suggests that the predicative phrase in a sentence like 37 is not the sister of the verb, which means, by virtue of 6 , that it is not an argument of the verb.

Thus we may conclude that the crucial difference between the illformed compounds in 34-36 and the well-formed ones in 38 is that the incorporated predicative expressions are arguments of the base verbs in the former but are non-arguments in the latter. An interesting case is the contrast between $34 \mathrm{a}$ and $38 \mathrm{~d}$; the verb catch in the sense of 'find unexpectedly', which takes a Pred argument, cannot form an -en compound as in 34a, but catch in the sense of 'seize' can appear in an -en compound as in $38 \mathrm{~d}$ because the predicative expression is a nonargument in this case. We find similar contrast between *free-set prisoners (cf. set the prisoners free) and *angry-made boys (cf. make the boys angry) on the one hand and the ready-set stage and ready-made parts on the other; in the former compounds, the verbs set and make are

${ }_{13}$ This argument does not hold in the case of the verb elect; they elected Reagan President implies that they elected Reagan. If our intuition that President in this sentence is the Pred argument of elect is correct, we may have to claim that elect, unlike, say, send in the causative sense, takes the Pred argument only optionally. This does not undermine our arguments; we can still maintain the claim that, if implicational relation fails to hold, the predicative expression must be analyzed as an argument of the verb. 
used in the causative sense and take Pred arguments, which is not the case with the latter compounds.

Returning to the contrast between 2 and 25, we also find that the predicative expressions are the arguments of the base verbs in 2, but are non-arguments in 25 . These observations lead us to claim that -en adjectives (whether in syntactic phrases or in verbal compounds) cannot take predicative expressions as their arguments. The property of rejecting Pred arguments is not peculiar to -en adjectives, but seems to be shared by adjectives in general:

(41) a. *John is visible tired.

b. *This fish is tasteful nice.

c. *His wife is sendable mad.

We also find the same property in nouns:

(42) a. *our election of a woman President

b. *the feeling smooth of silk

Hence we are led to the following claim: ${ }^{14}$

(43) Adjectives and nouns cannot take Pred arguments.

Then, if the argument structure of a derived adjective or noun contains a Pred argument as the result of inheritance of the argument structure of the base verb, that adjective or noun is ruled out as ill-formed.

Given 43, our framework can take care of the data in 34-36 and 38. A verb that takes two non-subject arguments Theme and Pred as in 29-31 cannot form an -en compound of the structure $23 \mathrm{~b}$ for the same reason as in the case of other verbs with more than two non-subject arguments; our principle 6 requires that both Theme and Pred be satisfied as sisters of the verb, but this is impossible because the verb has only one sister in $23 \mathrm{~b}$. The structure $23 \mathrm{a}$ is impossible with this type of verbs, because the -en suffixation to these verbs results in the argument structure (Theme, Pred), which is ruled out by virtue of 43 . Hence the compounds in 34-36 are ill-formed in either structure.

Compounds like those in 38 are well-formed only with the structure 23a. A verb appearing in this type of compounds has the argument structure (Agent, Theme). If this verb appears in $23 \mathrm{~b}$, the principle 6 requires that $\alpha$ be interpreted as the Theme argument, but this is not the case with the compounds in 38 , so that these compounds cannot have

${ }^{14} 43$, as it stands, is a stipulation, but hopefully it may follow from some general (presumably semantic) properties of nouns and adjectives (or $[+\mathrm{N}]$ categories). 
the structure 23b. On the other hand, the suffix -en can be attached to a verb of this type to derive an adjectival passive with the argument structure (Theme), so that the structure 23a is well-formed if $\alpha$ is given a non-argument interpretation. Because the predicative expressions incorporated in the compounds in 38 are non-arguments, these compounds are acceptable. In other words, compounds like 38 have exactly the same structure as other productive -en compounds with diadic verbs such as oven-roasted, Indian-made, factory-frozen, and the like, where non-head elements are interpreted as non-argument instrument, agent, locative, and so on; 'predicative' is one of the types of interpretation which non-arguments can bear.

In this section, we have seen that, in -en compounds, Pred arguments cannot be incorporated whereas non-argument predicative expressions can, and that, given 43 , the distribution of these compounds is correctly predicted in our framework.

4. -ing/-er compounds. Let us turn to verbal compounds with the suffix -ing or -er that incorporate predicative expressions. We find wellformed -ing compounds like the following (cited from Meys 1975: 143):

(44) a. a good-looking man

b. similar-seeming crimes

c. carbolic-smelling stairs

d. bureaucratic-sounding terms

e. pleasant-tasting tablets

The verbs appearing in these compounds undoubtedly have the argument structure (Theme, Pred). ${ }^{15}$ Given 43, -ing suffixation to this type of verbs results in ill-formed adjective or noun because the Pred argument is inherited. Therefore, the structure $45 \mathrm{a}$ is impossible for compounds like 44 , so that $45 \mathrm{~b}$ remains as the only possibility.

(45)

a.

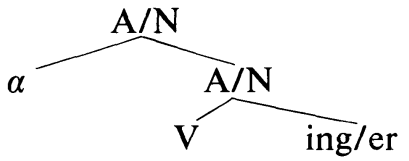

b.

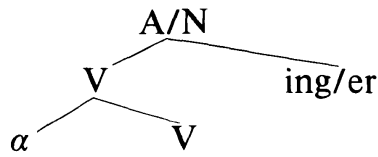

In our framework, nothing rules out the structure $45 \mathrm{~b}$ with this type of verbs; unlike the suffix -en, the suffix -ing does not involve such

15 Though the subject of seem is usually analyzed as a non-argument, the following example strongly suggests that the subject is an argument of seem (though this may not be always the case): John tried to seem insane. 
change in argument structure as 18 , so that -ing can be suffixed to the compound verb, say, good-look. . Thus the compounds in 44 are well-formed with the structure 45b, where $\alpha$ is interpreted as the Pred argument of the verb.

As Roeper and Siegel 1978 observe, we do not find -ing compound nouns incorporating predicative expressions for some unknown reason. But we find some -er compound nouns acceptable with Pred arguments incorporated:

(46) a. a good-looker

b. a handsome-looker

These examples, like those in 44 , are well-formed with the structure $45 \mathrm{~b}$, because the suffix -er, like -ing, does not involve a change in argument structure like 18 .

Thus, in our framework, it is correctly predicted that compounds like 44 and 46 are acceptable.

5. Summary. We have seen that the seemingly complicated distribution of data like 3-5 can be accounted for in our framework. Given the observation that adjectives and nouns do not take Pred arguments, the principle 6 leads to the claim that the structure 13b but not the structure 13a is a possible candidate for incorporating Pred arguments. Because -en compounds (except for the type air-conditioned), unlike -ing/-er compounds, cannot have the b-type structure, the contrast between, say, *selfish-labeled and good-looking is predicted. The difference in ability to take the b-type structure need not be stipulated, for it follows from the difference between the suffix -en, which involves the change in argument structure given in 18, and the suffixes -ing and -er, which do not involve such change.

Our framework is crucially different from that of Selkirk 1982 in assuming the two structures $13 \mathrm{a}$ and $13 \mathrm{~b}$ for verbal compounds, from that of Lieber 1983 in assuming that the argument structure of [V-suf $]_{\mathrm{N} / \mathrm{A}}$ is relevant in the structure 13a, and from both of the two in assuming that the suffix -en derives an adjective directly from a verb. These crucial assumptions of our framework are not only well-motivated, as we discussed in $\$ 2$, but also necessary to account for our data. If we assumed as in Selkirk that only one structure 13a is possible for all types of verbal compounds, our account would obviously be impossible, because it depends on assigning the structure $13 \mathrm{~b}$ to compounds like good-looking. If we assumed as in Lieber that only verbs 
have argument structures, our account, which depends on the property of argument structures of adjectives and nouns expressed in 43, would also be impossible. Finally, if we assumed that an adjectival passive is derived from the corresponding passive participle of a verb as in Selkirk or Lieber, our account would also fail; we would wrongly predict that compound adjectives like *selfish-labeled would be well-formed, for they could have the following structure:

(47)

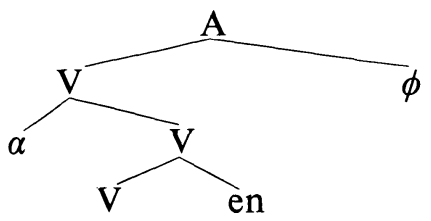

Because V-en is a verb rather than an adjective in $47, \alpha$ could be the Pred argument of the verb.

Thus, the data discussed in the preceding sections seem to be accountable only in the framework proposed in this paper.

\section{REFERENCES}

Adams, Valerie. 1973. An introduction to modern English word-formation. London: Longman.

Allen, Margaret Reece. 1978. Morphological investigations. University of Connecticut dissertation.

JACKENDOFF, RAY S. 1972. Semantic interpretation in generative grammar. Cambridge, MA: MIT Press.

LIEBER, RochelLE. 1983. Argument linking and compounds in English. LI 14.25185 .

Meys, W. J. 1975. Compound adjectives in English and the ideal speaker-listener. Amsterdam: North-Holland.

Quirk, Randolph, Sidney Greenbaum, Geoffrey Leech, and Jan Svartvik. 1972.

A grammar of contemporary English. London: Longman.

Roeper, Thomas and Muffy E. A. Siegel. 1978. A lexical transformation for verbal compounds. LI 9.199-260.

Selkirk, Elisabeth O. 1982. The syntax of words. Cambridge, MA: MIT Press. Wasow, Thомas. 1977. Transformations and the lexicon. Formal Syntax, ed. by Peter W. Culicover, Thomas Wasow, and Adrian Akmajian, 327-60. New York: Academic Press.

Williams, Edwin. 1981. Argument structure and morphology. Linguistic Review 1.81-114. 1984. Grammatical relations. LI 15.639-73. 